\title{
Introduction to Raw Material Quality of Asphalt Pavement Construction
}

\author{
Yizhen Yang ${ }^{a}$,Hong Gan ${ }^{b}$ \\ College of Civil Engineering and Architecture, Anhui Polytechnic University, 8 Beijing Road in Wuhu, \\ China 241000 \\ ayyiz2006@163.com, ’gh@ahpu.edu.cn
}

Keywords: Asphalt concrete, Coarse aggregate, Fine aggregate, grain composition

\begin{abstract}
In terms of domestic, road surface is divided into cement concrete and pavement of asphalt concrete. Asphalt concrete pavement has the characteristics of fast repair, low noise. So is a good use of asphalt pavement quality of road, but if you want to play to the performance of the asphalt surface, should have the quality guaranteed the quality of the raw materials for the construction. This paper discusses the raw material quality control.
\end{abstract}

\section{Introduction}

Asphalt roadbed early damage often is the use of material is bad, low degree of compaction, grading variability slants big, unreasonable drainage design and etc. To give full play to the advantages of asphalt concrete pavement, there must be a good raw materials of construction as a guarantee. Asphalt concrete to ensure that the desired design goal and the use of performance, it must be careful to do a good job of raw material quality control during construction.

\section{Asphalt Concrete Needs Pavement Materials}

Asphalt concrete pavement are required for materials with stones, stone, asphalt, emulsified asphalt additives, kuangfen, at a high speed of SMA modified asphalt also use wood fiber.

\section{The Quality of Raw Materials}

Material quality of technical indicators can be measured in crushing value, Los Angeles abrasion loss, density, the asphalt content of adhesion, sturdiness, soft stone, stone material sources, such as edges and indicator; Needle flake particle content, such as silt processability index. Material sources indicators value associated with the processing of gravel stone stone, with smaller correlation processing way [1]. Processing of rubble on fixed material sources, therefore, the index values are relatively stable. In aggregate quality control process, the author thinks that the quality control of processability index should be considered. Asphalt concrete mixing station in choosing material sources to choose good production stability, stone, mesh configuration to match the screen mesh and mixing station stones processing production.

\section{Raw Materials Division}

Coarse Aggregate. Coarse aggregate is to point to in the asphalt mixture of gravel, broken gravel size greater than $2.36 \mathrm{~mm}$, screening, gravel, slag, etc. Asphalt mixture quality requirements of the coarse aggregate used as shown in table 1.

Coarse aggregate particle size specification should be production and use according to the provisions of the table 2 .

Quarries in the process of production must be thoroughly remove cover and soil intercalation [2]. In the production of gravel with rough stone shall contain a clod, sundry, aggregate products shall not be piled up in the dirt.

Fine Aggregate. Fine aggregate including natural sand and stone chips, mechanism of sand. It 
must be by the production license of the quarry, mining field production. Sphalt mixture with fine aggregate quality requirements as shown in table 3.

Table 1 Asphalt mixture quality requirements of the coarse aggregate

\begin{tabular}{|c|c|c|c|c|}
\hline \multirow{2}{*}{ Indicators } & \multirow{2}{*}{ Unit } & \multicolumn{2}{|c|}{$\begin{array}{l}\text { Senior highways and } \\
\text { first-class highway }\end{array}$} & \multirow{2}{*}{$\begin{array}{l}\text { Other grades } \\
\text { highway }\end{array}$} \\
\hline & & $\begin{array}{c}\text { Surface } \\
\text { layer }\end{array}$ & Other layers & \\
\hline Stone crushing value is not greater than & $\%$ & 26 & 28 & 30 \\
\hline Los Angeles abrasion loss is no more than & $\%$ & 28 & 35 & 35 \\
\hline The apparent relative density is no less than & - & 2.60 & 3.0 & 2.45 \\
\hline Bibulous rate is not greater than & $\%$ & 2.0 & 12 & 3.0 \\
\hline Robustness is no more than & $\%$ & 12 & 12 & - \\
\hline Needle flake particle concentration is no more than & $\%$ & 15 & 18 & 20 \\
\hline Particle size is greater than $9.5 \mathrm{~mm}$, not greater than & $\%$ & 12 & 15 & - \\
\hline Particle size is less than $9.5 \mathrm{~mm}$, not greater than & $\%$ & 18 & 20 & - \\
\hline $\begin{array}{l}\text { Water washing method is less than } 0.075 \mathrm{~mm} \\
\text { particles content, not greater than }\end{array}$ & $\%$ & 1 & 1 & 1 \\
\hline Soft stone content, not greater than & $\%$ & 3 & 5 & 5 \\
\hline
\end{tabular}

Table 2 Coarse aggregate particle size specification

\begin{tabular}{ccccccccccc}
\hline \multirow{2}{*}{$\begin{array}{l}\text { Name } \\
\text { specification }\end{array}$} & $\begin{array}{l}\text { Nominal } \\
\text { diameter } \\
(\mathrm{mm})\end{array}$ & \multicolumn{7}{c}{ Through the following mesh(mm) quality percentage(\%) } \\
\hline S1 & $10-25$ & - & 100 & $90-100$ & - & $0-15$ & - & $0-5$ & - & - \\
S2 & $10-20$ & - & - & 100 & $90-100$ & - & $0-15$ & $0-5$ & - & - \\
S3 & $10-15$ & - & - & - & 100 & $90-100$ & $0-15$ & $0-5$ & - & - \\
S4 & $5-15$ & - & - & - & 100 & $90-100$ & $40-70$ & $0-15$ & $0-5$ & - \\
S5 & $5-10$ & - & - & - & - & 100 & $90-100$ & $0-15$ & $0-5$ & - \\
S6 & $3-10$ & - & - & - & - & 100 & $90-100$ & $40-70$ & $0-20$ & $0-5$ \\
S7 & $3-5$ & - & - & - & - & - & 100 & $90-100$ & $0-15$ & $0-3$ \\
\hline
\end{tabular}

Table 3 Sphalt mixture with fine aggregate quality requirements

\begin{tabular}{cccc}
\hline project & unit & $\begin{array}{c}\text { Senior highways and } \\
\text { first-class highway }\end{array}$ & $\begin{array}{c}\text { Other grades } \\
\text { highway }\end{array}$ \\
\hline The apparent relative density, not less than & - & 2.50 & 2.45 \\
Robustness, not less than & $\%$ & 12 & - \\
The content of silt content, no more than & $\%$ & 3 & 50 \\
Sand equivalent to not less than & $\%$ & 60 & - \\
Methylene blue value is not greater than & $\mathrm{g} / \mathrm{kg}$ & 25 & - \\
Edges and corners is no less than & $\mathrm{s}$ & 30 &
\end{tabular}

Asphalt mixture with the specifications of the mechanism sand or stone chips as shown in table 4 . 
Table 4 Asphalt mixture with the specifications of the mechanism sand or stone chips

\begin{tabular}{ccccccccccc}
\hline specifications & $\begin{array}{c}\text { Nominal } \\
\text { diameter } \\
\text { (mm) }\end{array}$ & \multicolumn{6}{c}{ The quality of the water washing method through the sieve pore percentage (\%) } \\
\cline { 6 - 12 } & $0-5$ & 100 & 4.75 & 2.36 & 1.18 & 0.6 & 0.3 & 0.15 & 0.075 \\
\hline S15 & $0-100$ & $60-90$ & $40-75$ & $20-55$ & $7-40$ & $2-20$ & $0-10$ \\
S16 & $0-3$ & - & 100 & $80-100$ & $50-80$ & $25-60$ & $8-45$ & $0-25$ & $0-15$ \\
\hline
\end{tabular}

Note: when the production of stone chips using hydraulic suppress dust process, should pay special attention to powder content must not exceed the requirements in the table.

System of Sand Production Requirements.Sand should adopt the system of special sand mechanism, and select high-quality stone production, its grading should accord with the requirement of S16.

Packing. Asphalt mixture of mineral powder must use the powerful basic rocks such as limestone or magmatic hydrophobic stone fine grinding of mineral powder, the original stone earth impurities should be cleaned out. Mineral powder should be dry, clean, can freely flow from mineral powder storehouse, its quality should meet the requirements of table 5.

Table 5 Mineral powder requirements

\begin{tabular}{|c|c|c|c|c|}
\hline project & unit & $\begin{array}{l}\text { Senior highways and } \\
\text { first-class highway }\end{array}$ & $\begin{array}{c}\text { Other grades } \\
\text { highway }\end{array}$ & $\begin{array}{l}\text { experimenta } \\
\text { l method }\end{array}$ \\
\hline The apparent density, not less than & $t / m^{3}$ & 2.50 & 2.45 & T0352 \\
\hline Moisture content, not greater than & $\%$ & 1 & 1 & T0103 \\
\hline Particle size range is less than $0.6 \mathrm{~mm}$ & $\%$ & 100 & 100 & \\
\hline less than $0.15 \mathrm{~mm}$ & $\%$ & $90-100$ & $90-100$ & T0351 \\
\hline less than $0.075 \mathrm{~mm}$ & $\%$ & $75-100$ & $70-100$ & \\
\hline aspect & - & $\begin{array}{l}\text { No aggregate } \\
\text { agglomerate }\end{array}$ & - & - \\
\hline Coefficient of hydrophilic & - & $<1$ & - & T0353 \\
\hline The plastic index & $\%$ & $<4$ & - & T0354 \\
\hline The heating stability & - & The measured records & - & T0355 \\
\hline
\end{tabular}

Mixer type of dust can be used as part of the recycling use. But each dish amount shall not exceed $25 \%$ of the total packing, packing plastic mixed with dust shall not be greater than $4 \%$.

Dosage of fly ash used as filler, shall not exceed $50 \%$ of the total, ignition loss should be less than $12 \%$ of fly ash and mineral powder mixture of plasticity index should be less than $4 \%$, the remaining ore quality requirements and the same. Highway, first class roads of asphalt layer should not be using fly ash to do packing.

Asphalt. Each level of asphalt scope as shown in table 6.

Table 6 Each level of asphalt scope

\begin{tabular}{cl}
\hline Asphalt grade & \multicolumn{1}{c}{ Scope of application } \\
\hline A grade asphalt & $\begin{array}{l}\text { Each level road, is suitable for any occasion and level } \\
\text { 1.Highway, highway, level 1 under the asphalt layer and the following level, level 2 and } \\
\text { below secondary highway at all levels; }\end{array}$ \\
B grade asphalt & $\begin{array}{l}\text { 2.Used as modified asphalt, emulsified asphalt, modified emulsified asphalt, diluted } \\
\text { asphalt matrix asphalt } \\
\text { Level 3 and level 3 under the highway at all levels }\end{array}$ \\
C grade asphalt
\end{tabular}

Asphalt label. Asphalt label with no. 160, no. 140, no. 110, no. 90, no. 70, no. 50 and no. 40 . Using asphalt has relationship with the regional climate, the region in the south of anhui normal use of no.70 A level asphalt and modified asphalt SBSI-D.

The Influence of Raw Materials of Asphalt Concrete

Stone Material Effect on the Gradation Composition.In the process of gradation composition, 
stone synthesis grading curve that accords with a requirement specification is a s-shaped, unreasonable gravel size grading curve variability prone to hump, and when mixed with finished product material overflow hot bin will happen [3]. To choose the aggregate size, the reasonable setting crusher mesh to reduce production aggregate gradation of variability; To keep balance of crusher production, help keep crushing gradation of aggregate stability.

The Influence of Stone Chips on Asphalt Mixture Density.Stone raw materials especially stone chips directly affect the density of asphalt mixture, too much powder is less than $0.075 \mathrm{~mm}$ asphalt mixture density is too large, the smaller voids, underneath the paving asphalt mixture layer against traffic road, it's easy to have a rut. Kuangfen must use the alkaline stone grinding stone powder, such as limestone shall not use acidic rock polished stone powder, mineral powder should be dry, clean, not cluster.

Stone Material the Needle Flake Content is too Large to Influence of the Asphalt.Aggregate needle flake particle content is large, the anti-rutting performance of asphalt mixture to drop, from the asphalt mixture Marshall test results, can be concluded that the same rule, but the difference is not so big rutting test, this is due to the way of experiment. Aggregate shape close to the cube, there is a clear edges, less needle flake particle, good mechanics performance of asphalt mixture, especially the high temperature stability is particularly important.

Aggregate Proportion and Water Absorption.The proportion of aggregate, bibulous rate on the mechanical strength of asphalt mixture, water stability, high temperature stability, have a significant impact. In order to get the asphalt mixture with good quality, first of all should choose smaller than major water absorption of aggregate stones, the stone is hard, dense texture mechanics performance is good, high mechanical strength of asphalt mixture. Aggregate the bibulous rate is not as small as possible, to share close to stone, bibulous rate is generally small stone surface smooth, unfavorable to asphalt adhesion, bitumen membrane is thinner, so the bibulous rate is between $0.3 \%$ and $0.7 \%$ of stone are more appropriate.

Aggregate of Hydraulic. The basic requirement of asphalt pavement with aggregate is dry and clean. For asphalt pavement with coarse aggregate is clean degree, technical specification for construction of asphalt pavement using silt content index control (i.e., less than $0.075 \mathrm{~mm}$ particles content).

Reduce the coarse aggregate of hydraulic measures mainly include:

(1) Strict control of processing stone clean degree. When shitang mouth has covered soil mining block, must be removed before mining stone clay layer, prevent soil pollution stone. For the same soil layer near the stone, because has been polluted, abandoned or rinse after use.

(2) When using the washing method and processing of gravel, must increase the water flushing frequency, make the aggregate thoroughly clean;

(3) Strengthening the field management, the aggregate must cover, otherwise the aggregate in processing yard secondary pollution by dust, coupled with the rain, silt content increased obviously;

(4) Yard to hardening, the use of concrete hardening treatment in the field, avoid forklift when charging, the soft soil layer, soil mixed with aggregate material in the heap;

(5) In the production of aggregate counterattack crusher must be equipped with dust removal equipment, and in the process of aggregate production, guarantee the normal work of the dust removal equipment. In this way can we reduce the silt content of coarse aggregate and fine aggregate particles less than $0.075 \mathrm{~mm}$.

\section{Conclusion}

Source of raw materials: try to choose large feeding, to ensure a steady supply of raw material and material sources.

Regular testing production line vibrating screen mesh, ensure the uniformity and stability of each material. This is very important, practice is easy to be ignored.

Specification material transport and storage: hardening mixing area, improve drainage facilities, raw materials piled separately and rational layout to prevent the mixing and pollution. To minimize 
the transfer deposit number, accumulation of different mechanical method will cause materials piled up different levels of segregation.

Is the functional role of the pavement construction of asphalt pavement, the last and most important part of the part is the essence of the whole project, it is the embodiment of real management, technology, equipment and so on a part of the comprehensive ability and level. We strengthen the quality control of asphalt concrete raw materials to improve the quality of asphalt pavement has obtained the good effect, will be further summarizes the experience, gradually improve, reduce the early damage of asphalt concrete pavement, increase its service life, play a greater economic benefit.

\section{Acknowledgements}

In this paper, the research was sponsored by the Wuhu Key Project (Project No. 2013cxy08) and College students' innovative entrepreneurial training project in Anhui Province "The detection, identification and reinforcement application research of structures”.

\section{References}

[1]Tao Sun, Min Wei, Xiaoli Fan. Asphalt concrete pavement construction quality control for raw materials[J]. Urban construction theory research:2011(21)

[2] Hong Gan, Yizhen Yang. Nonlinear dynamic analysis of the damping frame structure system. Advanced Materials Research,2012 the civil, structural and environmental engineering international academic conferences.

[3] Hong Gan, Yizhen Yang. Application research on base isolation building structure [J]. Journal of AnHui Polytechnic University,2013.6 